\title{
Digital Signal Processor and Energy Control
}

\author{
Yutaka Nishikori (1),(2), Yoshimichi Nakamura (3),(2), \\ Hirofumi Matsuo (2) \\ (1)Texas Instruments Japan Limited, (2)Nagasaki University, \\ (3)WINZ Corporation.
}

\begin{abstract}
Power supply was consisted of several analog parts and various circuits had been conventionally researched before. While, digitalization research of power supply is proceeding, but it has some problem of performance and cost to create digital control power supply. Now the revolution is occurred at Energy Control area after appearing DSP (Digital Signal Processor). Until now, a power supply was one of component of system. However, the digital control power supply using DSP can realize more intellectual system and power supply is going to change from one of component to a part of system. This paper deals with the evolution of DSP and how to make impact to energy control system. Also, we will consider future application for energy control systems.
\end{abstract}

\section{INTRODUCTION}

Now a major social problem of global warming, energy is one of important element in the world. It's an important element for achieving a low carbon society how to utilize energy efficiently. As part of the energy-saving green IT has been proceeding all over the world. But green ET (Embedded Technology) is also important element. This green ET can realize a low carbon society to connect energy and information by power supply

To realize green ET, different type of intelligent power supply will be required against legacy power supply. Because, future power supply system needs to control power of total system to communicate each other. Then digitalization of power supply is very important to realize intelligent power supply. Digitalization research of power supply was proceeding before, but could not appear practical products due to performance and cost issues. But now, development of digital control power supply is accelerated due to the appearance of high performance and low cost DSP.

DSP(Digital Signal Processor) is the processor specified for the digital signal processing. more than 25 years have passed after appearing this product in the world. At first time, this processor was developed for the military application. However, now DSP was applied on various application such as control, voice, audio and image processing. Therefore, DSP is one of the most important processor in the present digital society.

When control applications such as HDD and motor control were moved from analog to digital, some DSP evolved to high speed control oriented DSP. Now this DSP is attracted attention for energy control processor. Fig 1 shows the rough MIPS requirement of DSP for each application.

FIGURE I

MIPS requirement of Control Application

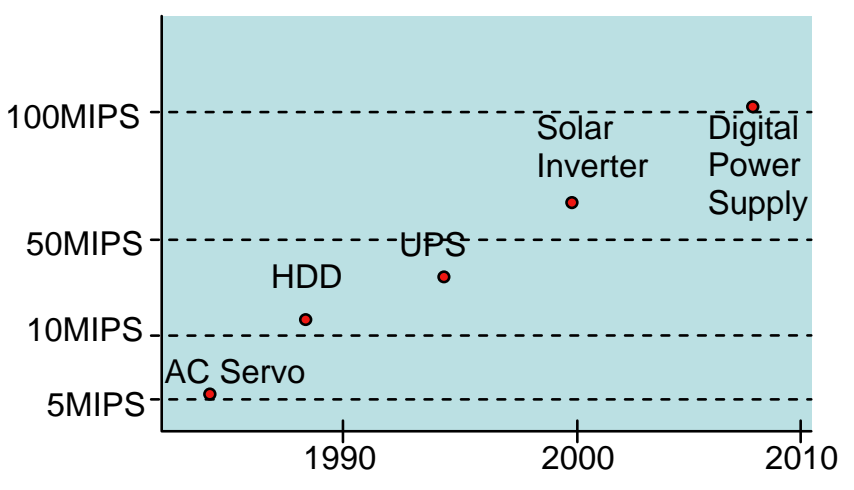

\section{HISTORY OF DSP FOR CONTROL APPLICATION}

\section{DSP for control application}

After appearing DSP at the beginning of year 1980, first control application using DSP was motor control. Specially, DSP was used for high speed AC servo motor control for industry application. At that time, system was consisted of several IC like a DSP, A/D converter and ASIC which has including PWM function. But due to limited space of board, DSP has to integrate several peripheral like an A/D converter and PWM. Now one chip micro controller is major which has integrated not only A/D converter, PWM, but also Flash memory for programming. These modules are useful for energy control system.

\section{Application for energy control}

In the energy field, DSP is used for the control of UPS (Uninterruptible Power Supply) and solar inverter. Now it's focused on the digital control power supply application and the future development is expected. The reason for employing DSP for energy control is some peripheral performance improvement with high frequency DSP development. Specially, A/D converter and PWM (Pulse Width Modulation) are most important modules for energy control. It was difficult to realize high speed switching of the digital control power supply using old one-chip DSP due to not enough performance of A/D converter and PWM. The current DSP for digital control system has 12bit resolution with 80ns conversion time A/D converter and 150ps very high resolution PWM. The appearance of DSP can easily 
realize the digital control power supply with high performance.

III. DSP FUNCTION REQUIREMENT FOR DIGITAL CONTROL POWER SUPPLY

\section{A/D converter}

One of important peripheral for digital control power supply is A/D converter. Digital control power supply needs to sense input voltage, output voltage and output current and control PWM output. A/D converter uses for sensing function. CPU senses voltage and current every time period and calculates control parameters, then controls system. The performance of control will go up when control period becomes shorter. So conversion time of $\mathrm{A} / \mathrm{D}$ converter will be important to improve system performance.

\section{PWM (Pulse Width Modulator)}

PWM is also important peripheral for digital control power supply. Output voltage of digital control power supply will be decided to control switching of power module by PWM output. So high resolution of PWM output can control detailed switching control of power supply. Picture I shows output voltage of digital power supply when using 10ns PWM resolution. At this figure, signal is unstable.

Picture I

PWM control using 10ns resolution

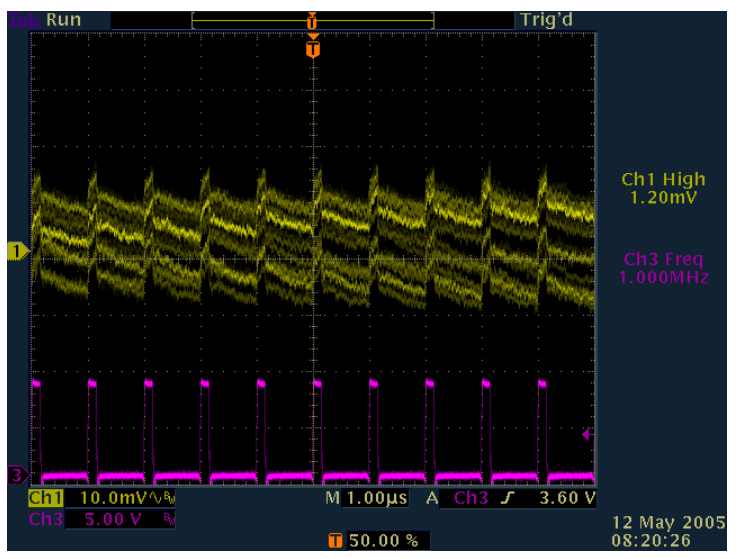

Picture II show output voltage of digital power supply when using 160ps PWM resolution. At this figure, signal is stable.
Picture II

PWM control using 160ns resolution

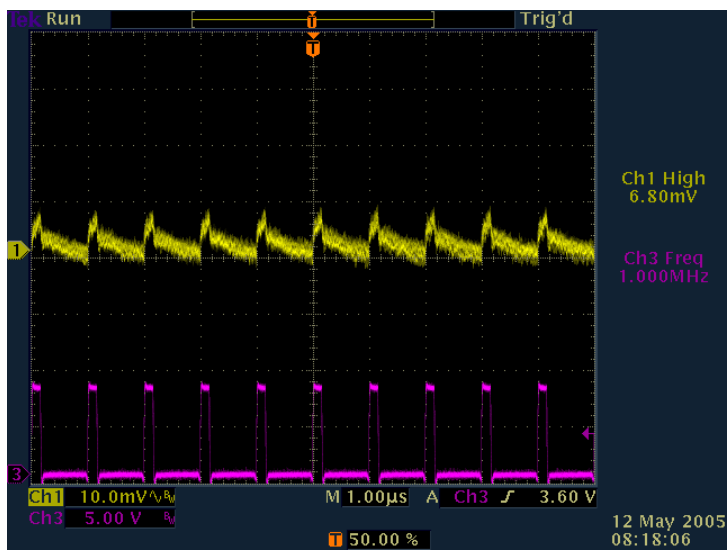

\section{DIFFERENT TYPE OF PROCESSOR FOR DIGITAL CONTROL POWER SUPPLY}

There are two types of processor for digital control power supply now. One is micro controller which has hardwired PID controller. It has not flexible feature like DSP, but this device has capability to change parameter from internal micro controller and can realize digital control power supply like a DC/DC POL. Figure II is dedicated digital control power supply IC named Fusion Power by Texas Instruments.

FIGURE II

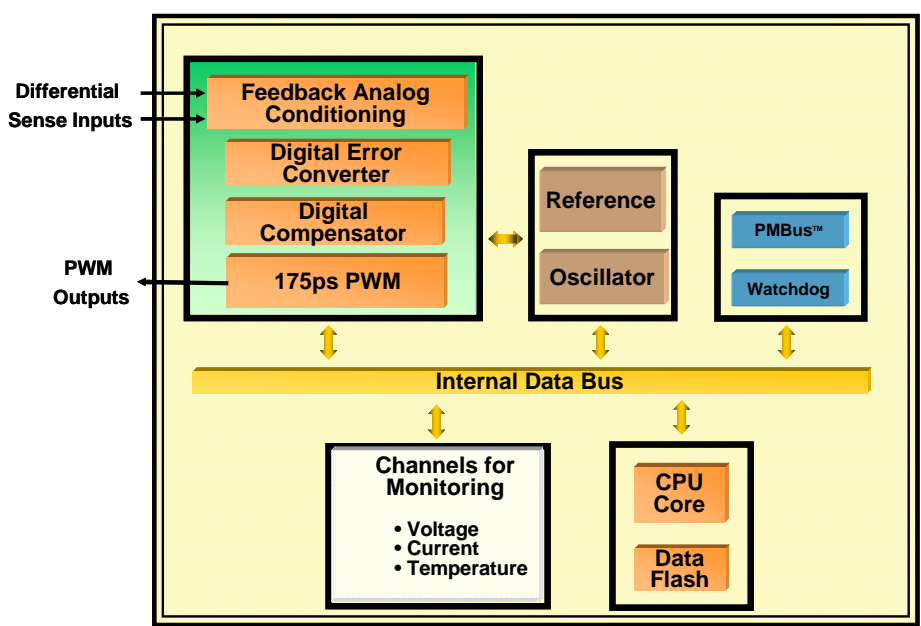

Fusion Power Digital control power supply IC

The other is DSP which is all programmable solution. Users can select these products depend on their system requirement. The programmable DSP can realize very flexible system. And it's possible to realize multi channel and multi phase power supply system using DSP. Also it's possible to support PFC (Power Factor Corrector) and communication function, 
Additionally, more evolved DSP architecture was announced and to reduce system cost and to improve the performance.

IV. CONTROL LAW ACCELERATOR TO REALIZE HIGH PERFORMANCE DIGITAL CONTROL POWER SUPPLY

TMS320F2803x DSP family from Texas Instruments integrates CLA (Control Law Accelerator) which is special module for control. For example, control feature like a PID is covered by CLA and other function like a parameter setting and communication is covered by CPU. Figure III shows block diagram of TMS320F2803x family. Both CPU and CLA can input analog data from A/D converter. After calculation both CPU can output data to PWM. But most of all control function can be done by CLA.

FIGURE III

Block Diagram of TMS320F2803x (Piccolo) DSP with CLA

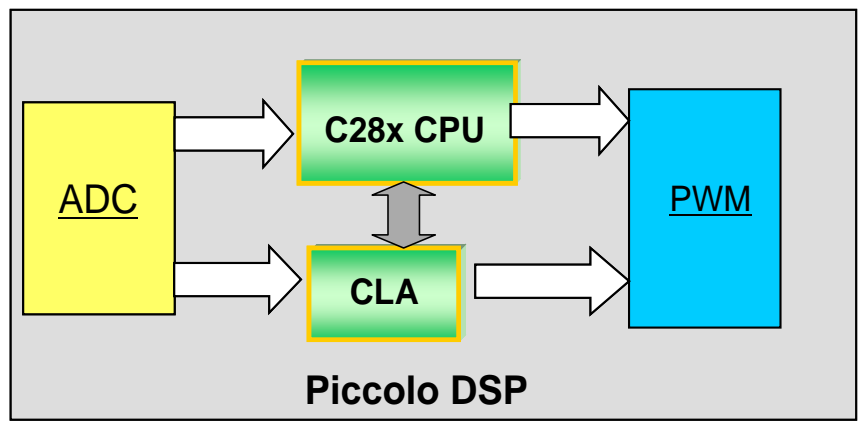

CLA has 32bit floating point calculation function and can get high accuracy calculation result. So control accuracy and performance is higher than legacy DSP. Figure IV is comparison of DSP and DSP+CLA when execute control algorithm.

FIGURE IV

Cycle comparison DSP vs DSP+CLA

\begin{tabular}{|l|c|c|}
\hline \multicolumn{1}{|c|}{ Operation } & $\begin{array}{c}\text { F28 } \\
(60 \mathrm{MHz})\end{array}$ & $\begin{array}{c}\text { F28/CLA } \\
(60 \mathrm{MHz})\end{array}$ \\
\hline Feed Forward control cycles & 482 & $482 / 0$ \\
\hline Feed Back control cycles & 1081 & $0 / 550$ \\
\hline Total Control cycles & 1563 & $482 / 550$ \\
\hline $\mathrm{MHz}$ Requirement & $32 \mathrm{MHz}$ & $10 / 11 \mathrm{MHz}$ \\
\hline
\end{tabular}

From result of this comparison, clock cycle of feedback control using CLA became half of existing DSP. TMS320F283x DSP has both CPU and CLA. So calculation of control algorithm was executed parallel

MIPS requirement will be $1 / 3$ of existing DSP. So TMS320F283x can reduce frequency of DSP or spend additional MIPS for other function. This means that new DSP can realize additional feature on digital control power supply.

Other merit to use CLA is to reduce overhead of cycle time by interrupt sequence. Then real time of system will be up.

\section{DIGITAL CONTROL POWER SUPPLY PLAT FORM USING DSP} When engineer develops digital control power supply using DSP, programming of DSP is required. It is much different from Analog power supply development. Specially, analog engineer is not familiar with DSP programming. So good development tool is required. Then we developed digital control power supply plat form using DSP with partner company. Picture III is digital control power supply plat form using TMS320F28035 DSP and Figure V shows block diagram of this plat form. In paper [1], digital control power supply plat form used $150 \mathrm{MHz}$ DSP named TMS320F2808 and realized digital control power supply. But at this time, used 60MHz TMS320F28035 (Piccolo DSP) and confirmed same performance.

One more important things to develop digital control power supply is software development environment. To develop digital control power supply system, easier development tool which has capability of object oriented method and small program module. Also need to use $\mathrm{C}$ or $\mathrm{C}++$ language rather than assembler language. At this time, I used Capsule Works which was developed by WINZ cooperation. This tool can satisfy these requirements. .

Picture III

Digital Power Supply Plat form using DSP

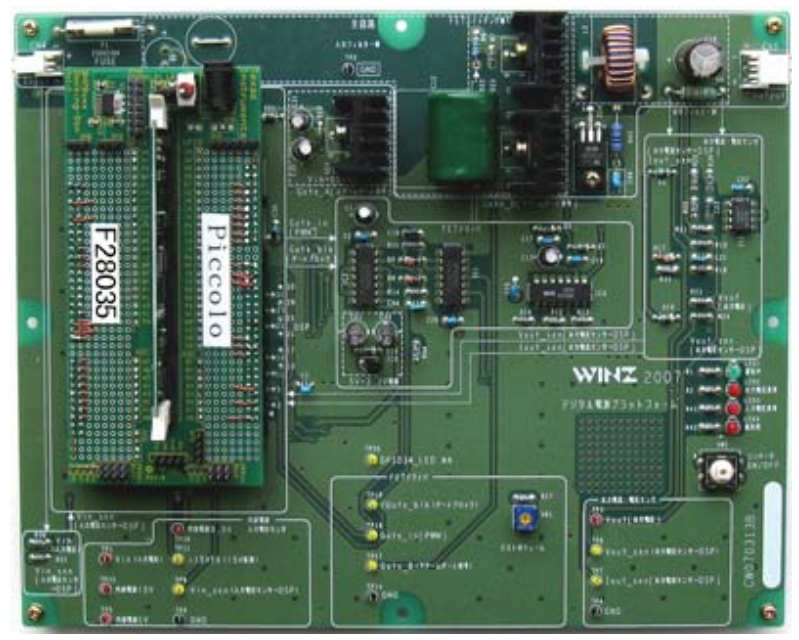


FIGURE V

Block Diagram of Digital Control Power Supply System

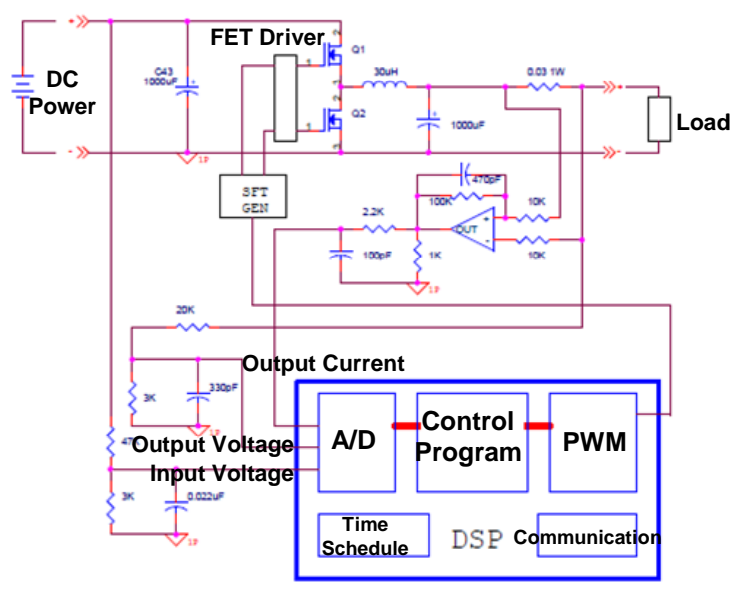

VI. MERIT OF DIGITAL CONTROL POWER SUPPLY

The one of merit to use DSP is multi function by high performance DSP. Specially, to use high performance DSP, multi phase power supply is realized by single DSP. Figure VI is example of multi phase digital control power supply. One DSP which has 16ch PWM output can realize 6 different output voltage and 14 kinds of multi phase.

\section{FIGURE VI}

Multi phase digital contorl power spply block diagram

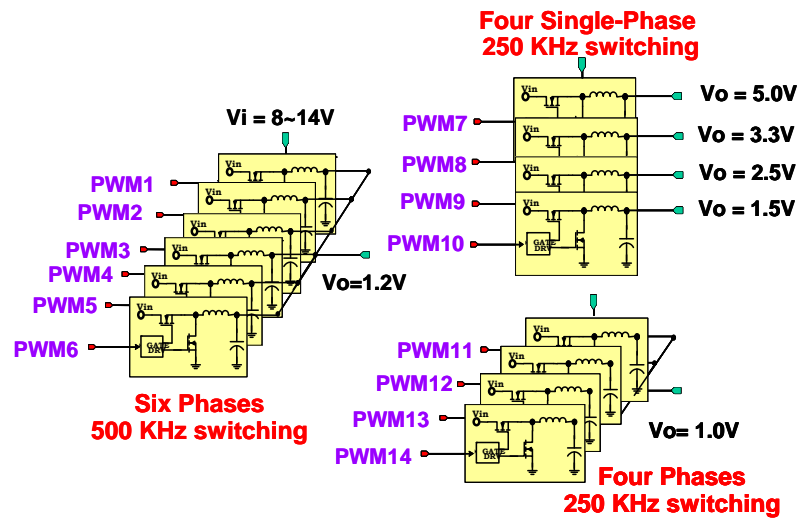

The other merit of digital control power supply is communication function. More intelligent system can realize using this function.

\section{COMMUNICATION FEATURE CREATES FUTURE DIGITAL CONTROL POWER SUPPLY}

With pricing reduction of DSP, energy control products will be changed in future. In the past, energy control system was developed as one system. But sometimes this system is consisted of several power modules and connected each other. It is highly possible that the total performance of this kind of system is high. The benefit to use digital control power supply units which is consisted of power module is short development cycle time and flexibility of system design. So power supply engineer does not need to know complex knowledge of system. Also it is possible that several power supply synchronizes each other. To match several power supply units create new energy control system.

Parallel connection of Power units (Capacity up) Serial connection of Power units (various products)

Figure VII shows class structure of digital control power supply.

FIGURE VII

Class structure of digital control power supply

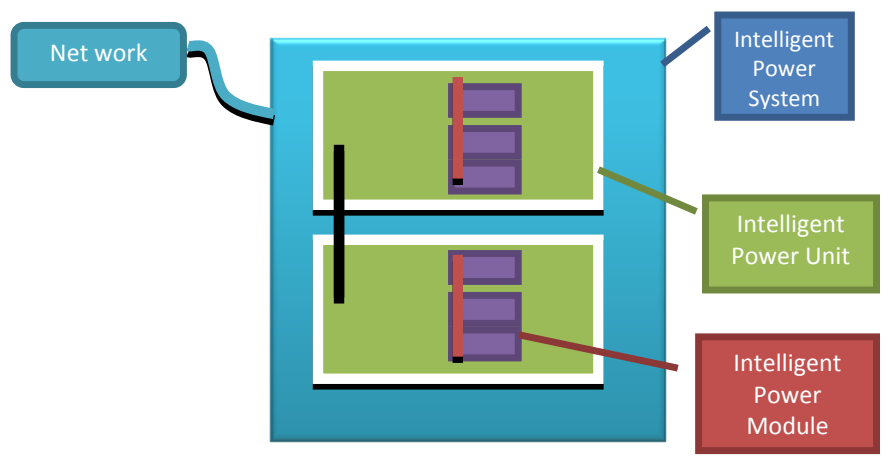

Communication function is most important element to realize Green ET. The control from out side of system was limited when use legacy power supply units. But to use DSP, system can react quickly to identify system condition.

1. Communication to identify condition of system

System monitoring is one of function to utilize communication feature. And system can identify condition of power supply quickly. .

\section{Communication to detect failure}

Failure detection is also important item, It is difficult to identify failure detection using legacy analog power supply module. To use DSP, power supply module can calculate power efficiency by itself. When the value falls below a certain power efficiency, power module sends alert to the system quickly. Then system can identify failure of power module before breaking module. This means that digital control power supply using DSP can increase reliability of system. 


\section{CONCLUSION}

At first time, DSP was developed for motor control application and expand to not only motor control but also energy control application. To employ DSP for energy control system like digital control power supply, new energy control system will contribute future Green IT and Green ET society. The key points to start employing DSP for power supply are high clock speed, high performance A/D converter and high resolution PWM on DSP. These items can realize multi function, multi phase and intelligent power supply. Also, after appearing new low cost DSP which has CLA module creates new market. This kind of products will be absolutely imperative future Green ET. Other merit to use DSP is communication function. To use communication function on power supply system, system will be able to identify system condition and detect failure of component. In the future, DSP will be key device in energy control area.

\section{REFERENCE}

[1]Yutaka Nishikori”Digital control power supply using high speed DSP and quasi-PID control” INTELEC 2008, P090

[2] Yoshimichi Nakamura, "The Design model is improves reliability of the embedded software” The Institute of Electronics, Information and Communication Engineers Conference, Japan, 2007, BS-6-4

[3]”'TMS320F28032/28033/28034/28035 Piccolo Microcontrollers (Rev.A) Data sheet” Texas Instruments Inc..SPRS584

[4]'TMS320x2802x, 2803 Piccolo Analog-toDigital Converter and Comparator Ref. Guidee” Texas Instruments Inc., SPRUGE5a

[5]"TMS320x2802x, 2803 Piccolo High-Resolution Pulse-Width

Modulator Reference Guide” Texas Instruments Inc., SPRUGE8a

[6]”TMS320x2803x, Piccolo Control Law Accelerator Reference Guide” Texas Instruments Inc., SPRUGE6 